\title{
A Reassessment of the Influence of Igbo Segmentals and Their Implications on the Teaching and Learning of English Sounds
}

\author{
Joekin Ekwueme \\ Department of English and Literary Studies, Faculty of Arts, University of Nigeria, Nsukka, Enugu State, Nigeria \\ Isaiah Ifeanyichukwu Agbo \\ Department of English and Literary Studies, Faculty of Arts, University of Nigeria, Nsukka, Enugu State, Nigeria \\ Zubairu Bitrus Samaila \\ Department of English and Literary Studies, Faculty of Arts, Taraba State University, Jalingo, Taraba State, Nigeria
}

\begin{abstract}
This paper reassessed the influence of Igbo segmentals on the teaching and learning of English sounds in the University of Nigeria Nsukka. It aimed to determine the extent to which phonological interference in Igbo language has negatively influenced the teaching and learning of the English phonemes. The study was anchored on Lado's (1957) theory of Contrastive Analysis Hypothesis (CAH). The data for study were elicited from a ten-item questionnaire which was randomly distributed to 50 First Year students of the Department of English, University of Nigeria, Nsukka. Again, the findings of previous researches were utilized to contrastively augment the primary data. Using both simple percentage system and Lado's framework, the data were analyzed quantitatively and qualitatively. The results showed that the recommendations of previous researches were yet to be fully implemented because there are still cases of language transfer at the level of phonology, particularly, the segmental level. Thus a good number of suggestions and recommendations were made to alleviate the problem.
\end{abstract}

Index Terms - segmentals, phonology, Igbo, English, linguistic interference, contrastive analysis

\section{INTRODUCTION}

The use of English as a second language in Nigeria is one of the most outstanding legacies which the colonial imperialists left behind after their departure from Nigerian soil prior to independence. Nigerians accepted to use English because the nation itself is multilingual. This language, therefore, enables Nigerians from different climes and cultures to communicate mutually for peaceful co-existence and meaningful development. Onuigbo and Eyisi (2008) confirm that the English language accommodates people of various cultures in a multilingual society like Nigeria and also link them with the international communities. We make bold to say that without the adoption of English as the nation's second language, we, as a nation, would have been experiencing language crisis by now. Since then the English language has continued to be functional in matters of Government, Business, Education, Media, Judiciary, Literature, Education, to mention just these. Particularly, since English is adopted as the medium of instruction in Nigerian schools as the National Policy on Education (NPE) (2010 as amended) stipulates, then it is not belittling to state that the teaching of English as a second language in Nigeria needs to be taken very seriously for the sake of international and cross-cultural intelligibility.

To attain some level of competence in the use of the English language by Nigerian speakers and writers, the user needs to be grounded in the five language levels: phonology, morphology, syntax, semantics and pragmatics. The mastering of these individual levels of language gives the second language learner an ample opportunity to communicate well with his neigbours. Nevertheless, the contact English made with other Nigerian indigenous language serve as one of the factors militating against the correct use of the language in Nigeria today. Ngonebu (2008) buttresses this point when she argues that when two languages come in contact, they are bound to mutually influence each other. The first language (L1) must definitely interfere in the learning and use of the second language (L2) because the language user may transfer the linguistic peculiarities of his Mother Tongue (MT) to the Target Language (TL) being learned. This form of inter-linguistic interference occurs most frequently in the area of phonology. No wonder Onuigbo (2016) argues that there is nothing like simple phonology as against what we have as simple sentence, grammar, vocabulary etc. Again, Onuigbo (2003) avers that "when one speaks, one produces a chain of speech sounds which are arranged in sequence to give syllables or words" (p. 1). If there is a shift in the phonological structure of a language, then the whole language structure is distorted.

It is, therefore, apparent that the structure of Nigerian Indigenous languages generally and Igbo in particular, differ significantly from that of English. Christophersen (1981) avers collaborates that the sound system of language is 
peculiar to that language, and that no other language has exactly the same system. He reiterates that despite the similarities that exist between two languages, there are usually far more differences. He further suggests that:

The learner of a new language must therefore realize that he is dealing with quite new sounds; he must not be satisfied to continue to use any of the sounds of his own language unless he is certain in each case that his own sound is exactly the same as that in the new language; he must not rest content until he has completely mastered all the sounds (Christophersen, 1981, p. 2).

The overt differences between phonologies of Igbo and English, to a greater extent, influence the correct pronunciation of English sounds in speech and writing. In the light this assertion, Ngonebu (2008) particularizes that many Nigerians encounter problems in the pronunciation of English words due to interference from mother tongue; the nature of consonant clusters in English; and lack of correlation between spelling and pronunciation of English words. This paper, therefore, is aimed to determine the extent to which phonological interference in Igbo language has negatively influenced the teaching and learning of the English phonemes; with the hope of making instrumental suggestions that would alleviate the problem.

\section{Problem Statement}

Research in cross linguistic interference is as old as language itself; however, the implementation of the previous researchers' suggestions and recommendations on the phonological interference of Igbo segmentals on the learning of English sounds seem not to have taken any serious effect. This is because, as lecturers in the Department of English, University of Nigeria, Nsukka, we observed with serious concern that students' use of English is sometimes marked by linguistic interference; particularly, in the area of phonology. Hence, one could not help but to conclude that the suggestions made by previous researchers have probably been swept under the carpet; this perhaps explains why this problem lingers. So, in order to alleviate this problem and to reemphasize the need to be phonologically correct in English by the Igbo speakers, we, therefore, attempt to reassess the influence of Igbo segmentals and their implications on the teaching and learning of English.

\section{THEORETICAL FRAMEWORK}

This paper adopts Lado's (1957) theory of Contrastive Analysis Hypotheses (CAH henceforth) as its analytic tool because the paper itself aims at expounding the similarities and dissimilarities that exist between Igbo and English segmentals and how the obvious differences affect the teaching and learning of English. CAH is an offshoot of Contrastive Analysis (CA henceforth) proposed by the same exponent. CA, according to Agbedo (2015: 93), "is the systematic comparison of two or more languages, with the aim of describing their similarities and differences." Agbedo goes further to explain that $\mathrm{CA}$ is geared towards providing better descriptions and teaching materials for language learners. The general assumption of $\mathrm{CAH}$ is that the native language plays a role in learning a second language. Structural similarities between the two languages being compared enhance the learning of a target language; while their dissimilarities hamper. Lado (1957) argues that CAH has three versions- (i) strong (ii) weak and (iii) moderate. Wardhaugh (1970) (as cited in Agbedo, 2015) proposes a distinction between a strong version and weak version of $\mathrm{CAH}$. The strong version involves predicting errors in a second language learning based upon a priori contrastive analysis of the first language. However, in the weak version, the analyst commences with learner errors and explicates them by pointing to the similarities and differences between the two languages being studied. It is however pertinent to note that these structural similarities or differences cut across the whole levels of language. Conversely, since this paper descriptively studies the phonological representation of Igbo and English segmentals; and their implication on pedagogical matters, the choice of this theory is valid and thus considers appropriate in this research.

\section{METHODOLOGY}

The study adopts a descriptive survey design because the design allows a researcher to select a representative sample from the entire population of the study. The sample of the study comprised fifty (50) First-year students in the Department of English and Literary Studies, University of Nigeria Nsukka, whose first languages are Igbo. Although there are other students of English in the university whose first languages are not Igbo, but this set students were not used in this study. More so, a ten-item questionnaire was designed and randomly administered directly to the selected students in order to elicit their responses on the influence of Igbo segmentals on the learning of English. However, out of fifty (50) questionnaires distributed, only forty-five (45) were duly completed and returned for analysis. The questionnaires were analyzed quantitatively using the simple percentage system; while the findings of previous researches were reanalyzed qualitatively in order to establish the similarities and differences which exist between the students' responses and previous researchers' findings. A detailed discussions followed suit using Lado's CAH as a guide.

\section{DATa ANALysis}


TABLE 1

ITEMS

DATA ELICITED FROM THE QUESTIONNAIRES

\begin{tabular}{|c|c|c|c|c|c|}
\hline \multirow[t]{2}{*}{ ITEMS } & \multicolumn{5}{|c|}{ OPTIONS } \\
\hline & SA & DA & SDA & $\mathbf{N}$ & Total \\
\hline \multicolumn{6}{|c|}{ 1. The dental fricative $/ \Theta /$ and $/ \delta /$ are the most problematic consonants for the Igbo speaker } \\
\hline No. of Respondents & $15(33.3 \%)$ & $8(17.7 \%)$ & $2(4.4 \%)$ & $5(11.1 \%)$ & $45(100 \%)$ \\
\hline \multicolumn{6}{|c|}{ 2. The voiced palatal fricative $/ z /$ is sometimes used as its voiceless counterpart $/ \mathrm{J} /$ or voiced palatal affricate $/ \mathrm{d} z /$} \\
\hline No. of Respondents & $24(53.3 \%)$ & $7(15.5 \%)$ & $6(13.3 \%)$ & $\mathbf{0}(\mathbf{0} \%)$ & $45(100 \%)$ \\
\hline \multicolumn{6}{|c|}{ 3. Insertion of additional sound segment (vowel) into certain positions of a word to break up consonant clusters } \\
\hline No. of Respondents & $21(46.6 \%)$ & $13(28.8 \%)$ & $4(8.8 \%)$ & $3(6.6)$ & $45(100 \%)$ \\
\hline \multicolumn{6}{|c|}{ 4. transfer the Igbo vowel system into English } \\
\hline No. of Respondents & $25(55.5 \%)$ & $6(13.3 \%)$ & $5(11.1 \%)$ & $\mathbf{0}(\mathbf{0 \%})$ & $45(100 \%)$ \\
\hline \multicolumn{6}{|c|}{ 5. The five orthographic representations of English vowels is another source of worry to the Igbo learner of English } \\
\hline No. of Respondents & $8(17.7 \%)$ & $5(11.1 \%)$ & $\mathbf{0}(\mathbf{0} \%)$ & $5(11.1 \%)$ & $45(100 \%)$ \\
\hline \multicolumn{6}{|c|}{ 6. The central vowels of English $(/ \mathrm{\Lambda} /, / 3: /$ and $/ \mathrm{\partial} /)$ are problematic to the Igbo learners and are released as $/ \mathrm{o} / \& / \mathrm{e} /$, respectively } \\
\hline No. of Respondents & $22(48.8 \%)$ & $2(4.4 \%)$ & $1(2.2)$ & $2(4.4 \%)$ & $45(100$ \\
\hline \multicolumn{6}{|c|}{ 7. Translation of words with double letters; treating the two letters as consonant clusters } \\
\hline No. of Respondents & $16(35.5 \%)$ & $12(26.6 \%)$ & $8(17.7 \%)$ & $2(4.4 \%)$ & $45(100 \%)$ \\
\hline \multicolumn{6}{|c|}{ 8. This spelling inconsistency is a big source worry to the Igbo learner/speaker of English } \\
\hline No. of Respondents & $22(48.8 \%)$ & $11(24.4 \%)$ & $4(8.8 \%)$ & $3(6.6 \%)$ & $45(100 \%)$ \\
\hline \multicolumn{6}{|c|}{$\begin{array}{l}\text { 9. The presence of labialized velar plosive and nasal consonants } / \mathrm{k}^{\mathrm{w}} /, / \mathrm{g}^{\mathrm{w}} / \text { and } / \mathrm{n}^{\mathrm{w}} / \text { in Igbo enhances the pronouncing of English plosive and nasal } \\
\text { sounds }\end{array}$} \\
\hline No. of Respondents & $24(53.3 \%)$ & $8(\mathbf{1 7 . 7 \%})$ & $2(4.4 \%)$ & $3(6.6 \%)$ & $45(100 \%)$ \\
\hline \multicolumn{6}{|c|}{ 10. Sometimes, Igbo learners realize English words containing / $/ /$ as $/ \mathrm{r} /$ and vice visa } \\
\hline No. of Respondents & $19(42.2 \%)$ & $11(24.4 \%)$ & $8(17.7 \%)$ & $5(11.1 \%)$ & $45(100 \%)$ \\
\hline
\end{tabular}

Item 1 shows that 30 respondents representing $66.6 \%$ agreed that the dental fricative $/ \Theta /$ and $/ \delta /$ are the most problematic consonants for the Igbo speaker; 10 respondents representing $22.2 \%$ disagreed; while 5 respondents representing $11.1 \%$ remained undecided. Item 2 reveals that $71 \%$ consented that the voiced palatal fricative $/ 3 /$ is sometimes used as its voiceless counterpart / $/$ / or voiced palatal affricate /dz/; while the remaining $29 \%$ refused. 1 tem 3 reveals that 55.5 accepted the insertion of additional sound segment (vowel) into certain positions of a word to break up consonant clusters; $37.7 \%$ did not accept they did; while $6.6 \%$ remained neutral. Item 4 shows that $75.5 \%$ agreed that the Igbo learner transfers the vowel system of Igbo into English; while 24.5\% disagreed. The fifth item reveals that $77.7 \%$ accepted that the five orthographic representations of English vowels is another source of worry to the Igbo learner of English but $11.1 \%$ disagreed and another $11.1 \%$ remained undecided. The sixth item reveals that $88.8 \%$ agreed that the central vowels of English $(/ \mathrm{\Lambda} /, / 3: /$ and $/ 2 /)$ are problematic to the Igbo learners and are released as $/ 0 / \&$ /e/, respectively; while the remaining $11.2 \%$ disagreed and remained neutral, respectively. Item 7 showed that $51 \%$ accepted that they translate words with double letters; treating the two letters as consonant clusters; $40.3 \%$ refused; while $4.4 \%$ remained neutral. Item 8 showed $60 \%$ agreed that the spelling inconsistency of English is a big source worry to the Igbo learner/speaker of English; $33.3 \%$ disagreed; while $6.6 \%$ were neutral. The ninth item revealed that $71 \%$ admitted that the presence of labialized velar plosive and nasal consonants $/ \mathrm{k}^{\mathrm{w}} /, / \mathrm{g}^{\mathrm{w}} /$ and $/ \mathrm{n}^{\mathrm{w}} /$ in Igbo enhances the pronouncing of English plosive and nasal sounds; while the remaining $29 \%$ did not. The last item shows that $46.6 \%$ agreed that sometimes, Igbo learners realize English words containing /1/ as /r/ and vice visa; $44.2 \%$ rejected that claim; while $11.1 \%$ remained undecided.

\section{DISCUSSION OF FINDINGS}

The English language recognizes the use of dental fricative sounds / $\Theta /$ and / $/$. But these sounds are completely absent in Igbo language and of course, other Nigerian languages. This perhaps explains while majority of respondents agreed that these sounds are problematic to the second language learner. Onuigbo (2003), Ngonebu (2008), Anagbogu, Mbah \& Eme (2010), and Nkamigbo (2010) confirmed that the Igbo learners of English found the dental fricative sounds too complex to pronounce. This difficulty may not be separated from their non-existence in Standard Igbo.

Similarly, voiced palatal alveolar fricative / $/$ / is absent in Igbo, but its voiceless pair / $/$ is much available in Igbo sound system. The Igbo learner of English, therefore, unconsciously uses $/ \mathrm{J} /$ in place of $/ 3 /$ because of the nonavailability of this sound in Igbo. No wonder $71 \%$ of respondents consented that the voiced palatal fricative /3/ is sometimes used as its voiceless counterpart $/ \mathrm{J} /$ or voiced palatal affricate $/ \mathrm{d} z /$. This usage, of course, constitutes a problem to the teaching of English sounds. In other words, palatal fricative $/ 3 /$ is another source of worry to the Igbo speaker.

More so, the clustering of consonants is a phonological feature which is closely associated with English because it permits the occurrence of two or more consonant sounds in a word without the interruption of a vowel sound. For example, the words 'street' /stri:t/ and 'plight'/plait/ contain the initial clusters of three and two consonants, respectively. Contrary to this, consonant cluster is not part of the features of Igbo sound system and as such, the Igbo learner unconsciously inserts an interrupting vowel to break up the cluster. This is why $55.5 \%$ of respondents agreed that they sometimes insert vowels amidst consonant clusters. According to Mangvwat (2003), many Nigerians have problem with consonant clusters because most Nigerian languages have a vowel following a consonant. He goes further 
to argue that where we have words with more than two consonant clusters, the Nigerian speakers of English find it very difficult to pronounce such words and the way out is usually to insert some vowel sounds to break up the clusters.

From the foregoing, it is pertinent to state that the Igbo learner transfers the Igbo vowel system into English. Just as Mangvwat has explained, the vowel in Igbo language almost always comes immediately after a consonant at the final position. This left many Igbo words open. However, the English language closes up most words with a consonant except in few occasions. The Igbo learner, therefore, opens up a closed word by inserting an additional vowel. This is further confirmed in item 4 where a significant number of respondents represented by $75.5 \%$ agreed that the Igbo vowel system is transferred into English during speech and writing. This usage is not only erroneous but also constitutes a problem in the teaching and learning of English sounds.

There are twenty vowel sounds in English. The vowels are represented by five letters of the English alphabet (A E I $\mathrm{O} \mathrm{U})$. These letters, to a greater or lesser degree, do not adequately represent the whole vowels of English. Anagbogu et al. (2010) consent that English vowels can have up to five or more different orthographic representations unlike in Igbo where each vowel is represented with only a letter of the orthography. This is probably why the vocalic symbols are extended to twenty to account for the vowels not represented in the letters of the alphabet. However, Onuigbo (2003) advises that we should not mistake the letters of the alphabet for speech sounds of the language. This form of (mis)representation constitute a problem to the Igbo learner because the eight vowels of the Igbo language adequately represent the whole vowels in the Igbo sound system; thereby making the identification and use of the vowels easy for the speakers. This argument justifies the reason why $77.7 \%$ of respondents consented that the five orthographic representations of English vowels is another source of worry to the Igbo learner of English.

Furthermore, the Non-availability of central vowels $(/ \mathrm{N} / \mathrm{/} / \mathrm{z}: /$ and $/ \mathrm{\partial} /)$ in Igbo is one of the major problems the Igbo learner of English has in learning and mastering of these sound segments. The learner is, therefore, left with no option than to use their equivalents. Onuigbo (2003) supports this assertion when he argues that learners of English generally tend to pronounce $/ \mathrm{N} /$ as $/ \mathrm{o} /$; he however, emphasizes that there is much qualitative difference between the two vowels. Little wonder why a significant majority represented by $88.8 \%$ agreed that the central vowels of English $(/ \mathrm{N} /, / 3: / a n d / \mathrm{a} /)$ are problematic to the Igbo learners and are released as /o/ \& /e/, respectively.

In another development, the Igbo speakers/writers of English, sometimes, transcribe words with double letters; treating the two letters as consonant clusters. This is a problem caused as a result of phonological interference. This type of linguistic interference "occurs when the speech patterns - phonemes, intonation, stress, or bulk of the phonemic system of the first language (L1) adversely affects the use of the second language" (L2) (Ngonebu, 2008: 22). In Standard Igbo, for instance, The double letters in each of these words: 'nwaany[' (woman) and 'taa' (today)are treated as individual sound segments. Consequently, the Igbo learner applies the same phonological principle in treating double consonant letters. Although item 7 in the questionnaire revealed that the number of respondents who agreed that they commit this type of phonological error do not show a significant difference with those who disagreed.

Again, the discrepancy between spelling and sound in English is another source of problem to the second language learner. The data showed that $60 \%$ of respondents admitted that spelling discrepancy is a big source worry to the Igbo learner/speaker of English. Consequently, the English language spelling system remains highly irregular. The sound that occurs in one pattern of spelling might be pronounced differently in another pattern of the same spelling. For example, the words "ought/د:t/, bough /bau/, dough/dəu/ and tough /tıf/" take this same pattern of spelling but are pronounced differently. On the other hand, the Igbo spelling system almost follow the same pattern. There are regularities in Igbo spelling as opposed to English. Our finding agrees with that of Ngonebu (2008) who explains that English is said to have one of the most difficult spelling systems in the world, as the written representation of English is not phonetically exact. She concludes that these differences in pronunciation are the reason why English is considered a difficult language for the non-native speakers to learn.

Item 9, as indicated on the table above, revealed that a good number of respondents agreed that the presence of labialized velar plosive and nasal consonants $/ \mathrm{k}^{\mathrm{w}} /, / \mathrm{g}^{\mathrm{w}} /$ and $/ \mathrm{n}^{\mathrm{w}} /$ in Igbo enhances the pronouncing of English plosive and nasal sounds. Although it is evidently clear that English does not make use of these plosive sounds. However, the similarities between English and Igbo sound, in this regard, facilitate the teaching and learning of the English plosive and nasal sounds. Lastly, there is not clear difference in the use of alveolar lateral /1/ and post alveolar approximant (roll) $/ \mathrm{r} /$ in the Igbo language. Some scholars attribute this usage to dialectal differences because it doesn't change the meaning of the word irrespective of the initial phoneme used. These same speakers tend to transfer this language use to English which constitute a big problem in language learning. Ngonebu (2008) elucidates that many Igbo speakers use the lateral /l/ in place of the liquid /r/. She goes further to exemplify that the Igbo speaker may pronounce the word 'bread' as 'bled'. These words have their different meanings as against what it is in Igbo language.

\section{CONCLUSION AND RECOMMENDATIONS}

This paper descriptively reexamines the phonological representations of Igbo and English segmentals; and their implications on pedagogical matters; using Lado's (1957) CAH. The foregoing reveals that the differences between English and Igbo Segmentals are heavily marked. This makes the assertion that "no two languages have exact phonological structure", true. The marked segmental differences constitute serious problems to the Igbo learners of English because the learners tend to transfer Igbo phonological peculiarities into English. This possibly explains why 
most university students performed poorly in phonetics and phonology assessments; and why they use language that sounds un-English in their spoken discourses. Although the influence of the source language on the learning of the target language is inevitable as far as language learning is concerned but the learner should aim at reducing the impact of this influence to the barest minimum. It is against this backdrop that the researchers suggest that these influences could be handled adequately by the language users themselves if they employ carefulness in their pronunciations of English words and expressions. Thus the users should always aim at pronouncing words correctly, taking note of the operations of different sound segments in their respective environments. Most importantly, language instructors (lecturers and teachers) should, as a matter of necessity, teach the second language learners the rudiments of the phonology of English and perhaps contrast it with other Nigerian indigenous languages. Again, instructors should not always teach English sounds in isolation, rather, sounds should be taught in connected speech. Also, instructors should encourage their students to listen to the recorded speeches of native English speakers and try to imitate the way they use language. Finally, the administrations of universities and of course, other institutions of higher learning in Nigeria should make provisions for functional language laboratories and ensure that these laboratories are put to use. It is our sincere belief that if these suggestions are implemented, the Igbo learner/speaker of English will be able to pronounce and transcribe English words and expressions with a high level of competence and accuracy.

\section{ACKNOWLEDGEMENTS}

We wish to express our profound gratitude to our research participants for their contributions which saw to the completion of this study. In the same way, we wish to acknowledge all other sources cited in the study. We are indeed grateful.

\section{REFERENCES}

[1] Agbedo, C. (2015). General linguistics: historical and contemporary perspectives. Nsukka: KUMCEE- Ntaeshe Press Inc.

[2] Anagbogu, P. N., Mbah, B.M. \& Eme, C.A. (2010). Introduction to linguistics second edition. Awka: Amaka Dreams Ltd.

[3] Christophersen, P. (1981). An English phonetics course. Harlow, Essex \& England: Longman Group Limited.

[4] Lado, R. (1957). Linguistic across culture. Ann Arbor: University of Michigan Press.

[5] Mangvwat, S. E. (2003). Oral English: a concise text for schools and colleges. Pankshin: Eureka Academic Foundation.

[6] Ngonebu, C.L. (2008). Fundamentals of second language. Nsukka: Afro-Orbis Publication Ltd.

[7] Nkamigbo, L.C. (2010). Phonology in teacher education in Nigeria: The Igbo language example. African Journal of Teacher Education, Vol. 1, No. 1. Pp. 48-63.

[8] Onuigbo, S. (2003). Oral English for schools and colleges (revised edition). Onitsha: Africana First Publishers Limited.

[9] Onuigbo, S. (20I6). Lecture note: University of Nigeria, Nsukka. Unpublished.

[10] Onuigbo, S. \& Eyesi, J. (2008). English language in Nigeria: issues and development. Nsukka: Global Publishers

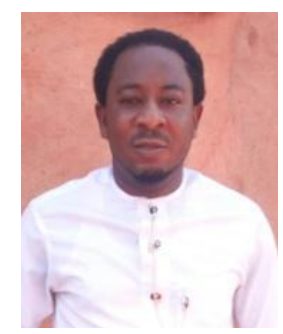

Joekin Ekwueme was born in Shendam, Plateau State, Nigeria on the 3rd March, 1987. He holds a Bachelor of Arts Degree in English/Education (B.A.Ed.), University of Jos; Master of Arts Degree in English (M.A.), University of Nigeria, Nsukka. He is currently pursuing his Doctor of Philosophy (Ph.D.) in the Department of English and Literary Studies, University of Nigeria, Nsukka. He had worked as a teacher and lecturer of English and Literature in secondary and adult Education Centers in some states of the federation. He had published articles in both International and Local journals; some of which are: "Impact of Social Media Language on the Writings of Undergraduates of University of Nigeria, Nsukka", International Journal of Arts and Humanities (2018). "Lexico-grammatical Readings of AdaOkere's The Forest Dames." International Journal of Applied Linguistics and English Literature (2018) "Systemic Textlinguistic Study of Kaine Agary's Yellow Yellow and Amma Darko's Faceless." Lamberts Academic Publishers, Germany (2018). His research interest includes: Textlinguistics, Applied English Linguistics, Semiotics, Stylistics and Pragmatics. Mr. Ekwueme is a member of Teachers Registration Council of Nigeria and English Scholar's Association of Nigeria.

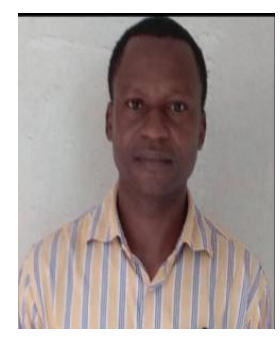

Isaiah Ifeanyichukwu Agbo is a lecturer in the Department of English and Literary Studies, University of Nigeria, Nsukka, Enugu State, Nigeria. He holds a Bachelor Degree, Master Degree and Doctorate Degree in English and Literary studies. He is a renowned scholar who has published many articles and book chapters in both international and local journals. His research interest is in ESL, Pragmatics, Applied Linguistics and English phonology. 


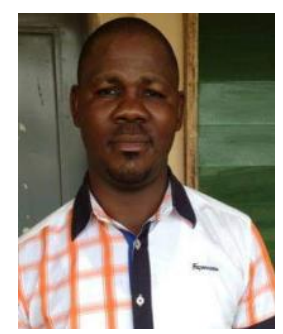

Samaila Bitrus Zubairu was born in Karim Maundi village of Karim Lamido Local Government Area of Taraba State on the 3rd May 1976. He holds B.A. English Language and M.A. English Language. He is currently pursuing his PhD in the Department of English and Literary Studies, University of Nigeria, Nsukka He worked with Taraba State Post Primary Schools Management Board 2003-2016 and rose through the rank of principal Education Officer. He is currently lecturing at the Taraba State University, Jalingo. Mr. Zubairu's research interest is in English Morphology, Applied Linguistics and Comparative Linguistics. He is a member of Teachers Registration Council of Nigeria. 